\title{
Effect of Lactic Fermentation and Spray Drying Process on Bioactive Compounds from Ngoc Linh Ginseng Callus and Lactobacillus plantarum Viability
}

\author{
Lieu My Dong ${ }^{1}$, Nguyen Thi Thuy Linh ${ }^{1}$, Nguyen Thi Hoa ${ }^{1}$, Dang Thi Kim Thuy ${ }^{2}$, and Do Dang Giap ${ }^{2}$ \\ ${ }^{1}$ Faculty of Food Science and Technology, Ho Chi Minh City University of Food Industry, Ho Chi Minh City 72009, Vietnam \\ ${ }^{2}$ Department of Plant Cell Technology, Institute of Tropical Biology, Ho Chi Minh City 71308, Vietnam
}

Received: June 26, 2021 / Revised: August 9, 2021 / Accepted: August 25, 2021

\begin{abstract}
Ngoc Linh ginseng is one of the most valuable endemic medicinal herbs in Vietnam. In this study, Ngoc Linh ginseng callus was fermented by Lactobacillus plantarum ATCC 8014 (at 6, 7, and 8 log CFU/ml) to evaluate the extraction efficiency of bioactive compounds. The post-fermentation solution was spray-dried using maltodextrin with or without Stevia rebaudiana ( $3 \%$ and $6 \%$ v/v) as the wall material. Bioactive compounds such as polyphenols, polysaccharides, and total saponins, and $L$. plantarum viability during fermentation and after spray-drying, as well as under simulated gastric digestion, were evaluated in this study. The results showed that probiotic density had a significant effect on bioactive compounds, and $L$. plantarum at $8 \log \mathrm{CFU} / \mathrm{ml}$ showed the best results with a short fermentation time compared to other tests. The total content of polyphenols, polysaccharides, and saponins reached $5.16 \pm 0.18 \mathrm{mg}$ GAE/g sample, $277.2 \pm 6.12 \mathrm{mg} \mathrm{Glu} / \mathrm{g}$ sample, and $4.17 \pm 0.15 \mathrm{mg} / \mathrm{g}$ sample, respectively after $20 \mathrm{~h}$ of fermentation at the initial density of $L$. plantarum $(8 \mathrm{log} \mathrm{CFU} / \mathrm{ml})$. Although there was no difference in the particle structure of the preparation, the microencapsulation efficiency of the bioactive compound in the samples containing $S$. rebaudiana was higher than that with only maltodextrin. The study also indicated that adding $S$. rebaudiana improved the viability of $L$. plantarum in gastric digestion. These results showed that $S$. rebaudiana, a component stimulating probiotic growth, combined with maltodextrin as a co-prebiotic, improved the survival rate of $L$. plantarum in simulated gastric digestion.
\end{abstract}

Keywords: Bioactive compounds, Ngoc Linh ginseng, Stevia rebaudiana, probiotic, spray drying

\section{Introduction}

Ngoc Linh ginseng has the scientific name of Panax vietnamensis $\mathrm{Ha}$ et Grushv, which belongs to the family Araliaceae. Sam Ngoc Linh is one of the most valuable and endemic medicinal herbs of Vietnam and has high economic value. Previous studies have shown that Ngoc Linh ginseng not only has pharmacological effects specific to the ginseng genus but also has typical pharmacological effects such as anti-cancer [1], anti-

\section{*Corresponding author}

Tel.: +84989961848

E-mail: lieudong289@gmail.com inflammatory [2], protect liver cells, anti-stress effect, anti-depressant, enhance memory [3] and many other diseases. Ngoc Linh ginseng with the main ingredient is the characteristic saponin that has the medicinal value of ginseng. Typical saponin compounds help promote health and have therapeutic effects. Among the saponins found, saponin majonoside-R2 (MR2) type is notable in its yield (5.3\% of dry rhizomes) [4]. Besides, ginseng also contains many other ingredients such as antioxidants, peptides, polysaccharides, fatty acids, vitamins, 18 amino acids, 20 trace minerals, essential oil content, etc. Therefore, the extraction of these bioactive compounds should be considered. However, overexploitation leads to 
a decrease in their natural supply. Hence, research for alternative sources ensuring medicinal activity in which in vitro callus culture of Ngoc Linh ginseng has shown potential source. The previous studies had demonstrated that callus cells of Ngoc Linh ginseng contained ginsenoside [5], phenolic compounds such as 5-O-caffeoylquinic acid, 5-O-feruloylquinic acid, etc [6]. These suggested that the callus culture could accumulate bioactive compounds like natural sources.

The methods extraction of bioactive compounds is used commonly in previous studies such as the effect of microwaves [7], assisted by ultrasound [8], heat reflux systems (Soxhlet) [9], etc. In addition to these mechanical agents, the use of microorganisms in the extraction of bioactive compounds from medicinal plants has also received much attention [10] due to the absence of thermal effects in the culture process or the use of toxic solvents. In previous studies have shown the potential of lactic acid bacteria in the extraction and metabolism of bioactive substances from plants [11]. The fermentation process disrupts the structure of the cell wall to release bioactive compounds and antioxidants [12]. Besides, the lactic fermentation process might improve the sensory properties and nutritional value, inhibit harmful microorganisms, and increase the storage time of products [13]. Additionally, lactic acid bacteria sources after the fermentation process play a role as probiotics, providing health benefits. Thus, fermented Ngoc Linh ginseng callus by lactic bacteria could not only improve the bioactive compounds but also provide a probiotic source. However, after the fermentation process, the bioactive compounds and probiotic source should be ensured and maintained during storage time, which the spray-drying technique could provide this value.

The spray-drying method transforms the liquid from the liquid to a fine-dried form by transferring the liquid to a hot drying medium [14]. This method can produce the purest and best-sized powder products under high aseptic conditions that can easily transport and increased storage time [15]. Besides, the spray-drying technique acts as a microencapsulation process that protects probiotic bacteria from adverse conditions such as preservation and simulated gastric digestion [16]. In the spray drying technique, the product could be in powder or flocculant form that depends on the properties of the wall materials and the spray dryer [14]. There are many wall materials, using for the spray drying process, of which maltodextrin is commonly used due to reducing cling, sticky, and increasing the free-flowing properties of the spray-drying powder [17]. To increase the protective efficiency during the spray drying process, the combination of wall materials was often used. Besides, the sensory property plays an important role in deciding the product choice of consumers in which the sweetness of the product is often concerned. Therefore, the supplement wall material for the spray drying process should ensure the protective efficiency of bioactive compounds and probiotic bacteria, as well as have a good taste. Previous studies showed that Stevia rebaudiana is one of the plants used to replace sugar, medicine, and food, especially a plant that can act as a sweetener (about 300 times more than sucrose) but low in calories [18]. Additionally, the stevia leaves have been proven to play the role of a prebiotic source [19]. Therefore, the combination of maltodextrin and stevia leaves as wall materials would help maintain the bioactive compounds of Ngoc Linh ginseng callus, the probiotic viability, as well as the sensory of the product. In this study, Ngoc Linh ginseng callus was fermented by Lactobacillus plantarum (ATCC 8014) to evaluate the extraction efficiency of bioactive compounds. The post-fermentation solution was spray-dried with maltodextrin and stevia leaves as the wall materials. Bioactive compounds such as polyphenols, polysaccharides, total saponins, and L. plantarum viability during fermentation and after spray-drying, as well as under simulated gastric digestion had evaluated in this study.

\section{Material and Methods}

\section{Material, microorganism strain, and culture conditions}

Aquilaria spp. leaves (Fig. 1) Ngoc Linh ginseng derived from Ngoc Linh Mountain, which is located at $15^{\circ} 04^{\prime} 00^{\prime \prime} \mathrm{N} 107^{\circ} 59^{\prime} 00^{\prime \prime} \mathrm{E}$ in the Central Highlands region of Vietnam. Ngoc Linh ginseng callus was cultured in the SH medium (SCHENK \& HILDEBRANDT) supplemented with $2 \mathrm{~g} / \mathrm{l}$ casein hydrolysate.

Microbiological strain: L. plantarum (ATCC 8014) from the Faculty of Food Science and Technology was cultured on MRS at $37^{\circ} \mathrm{C}$ for $24 \mathrm{~h}$. Biomass was collected by centrifuge (Z206A, Hermle, Germany) and suspended in $10 \mathrm{ml}$ of saline water $(0.9 \% \mathrm{w} / \mathrm{v})$ for the 


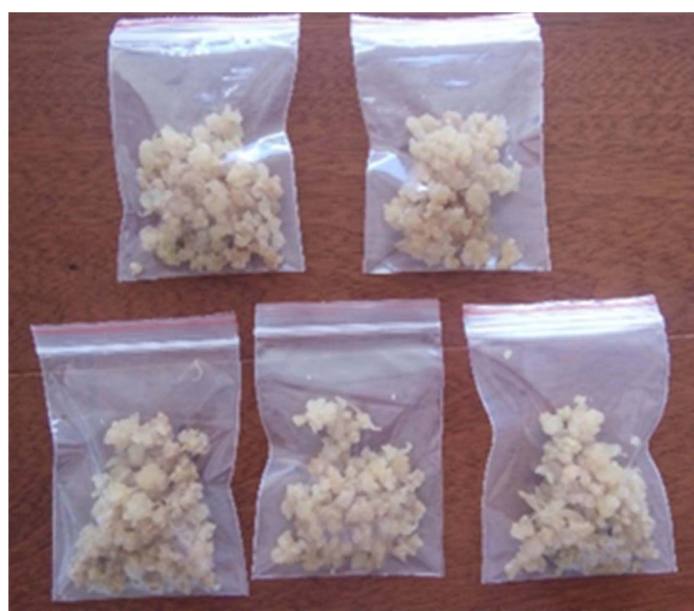

Fig. 1. Ngoc Linh ginseng callus.

fermentation process.

Stevia (Stevia rebaudiana) after collecting samples in Hung Yen province, which is located at $20^{\circ} 39^{\prime} \mathrm{N}$ $106^{\circ} 04^{\prime} \mathrm{E}$ in the northern part of Vietnam. Dried Stevia leaves were extracted with water at the rate of $1: 25(\mathrm{w} / \mathrm{v})$ at $65^{\circ} \mathrm{C}$ for $3 \mathrm{~h}$. The extracted fluid was used for the spray drying process.

\section{Effects of the fermentation process on Ngoc Linh ginseng extract}

Biomass of Ngoc Linh ginseng callus (Fig. 1) weighed accurately ( $2 \mathrm{~g} \pm 0.01)$ crushed, extracted with distilled water twice at the rate of 1:35 (w/v). The callus biomass extract was then supplemented with strains of bacteria L. plantarum (reaching concentrations of 6, 7, and $8 \mathrm{Log}$ $\mathrm{CFU} / \mathrm{ml}$ ) and fermented at $37^{\circ} \mathrm{C}$. Samples were examined for bioactive compounds and $L$. plantarum viability every $4 \mathrm{~h}$ and last for $48 \mathrm{~h}$.

\section{Effects of sweetgrass in the spray drying process of Ngoc Linh ginseng extract}

Ngoc Linh ginseng extract after fermentation was supplemented with $15 \%$ maltodextrin (Himedia, India) with or without stevia leaves extract ( $3 \%$ and $6 \% \mathrm{v} / \mathrm{v})$. The mixture was then spray-dried (SD-1000, Eyela, Japan) according to the spray structure with the following parameters: input flow $30 \mathrm{~m}^{3} / \mathrm{h}$, nozzle diameter $0.71 \mathrm{~mm}$, the pressure was $2 \mathrm{~atm}$, the inlet temperature was $120^{\circ} \mathrm{C}$, outlet temperature was $65-75^{\circ} \mathrm{C}$. Sample spray drying without Stevia leaves extract was consid- ered as the control samples. The preparations after spray-drying were evaluated the particle shape by a scanning electron microscope (SEM). The content of bioactive compounds and L. plantarum viability before and after spray drying was examined to evaluate microencapsulation efficiency (ME\%) by the following formula.

$$
M E \%=\frac{\begin{array}{c}
\text { Content of bioactive conpounds or density } \\
\text { of } L \text {. plantarum after drying }
\end{array}}{\begin{array}{c}
\text { Content of bioactive conpounds or density } \\
\text { of } L \text {. plantarum before drying }
\end{array}} \times 100 \%
$$

\section{Analytical methods}

Determination of total polyphenol content. The total phenolic content was performed as described by Leamsomrong et al. [20] with some changes summarized as follows: $1 \mathrm{ml}$ of sample was added $5 \mathrm{ml}$ of Folin-Denis reagent, mix, let the reaction take place for $3 \mathrm{~min}$, then add $4 \mathrm{ml} 7.5 \% \mathrm{Na}_{2} \mathrm{CO}_{3}$ solution. Allow standing for $60 \mathrm{~min}$. The absorbance was measured with a wavelength of $765 \mathrm{~nm}$. Results are expressed in $\mathrm{mg}$ gallic acid equivalent per gram of sample (mg GAE/g sample) based on the gallic acid calibration curve.

Total polysaccharide content determination. The total polysaccharide content was conducted as described by Lieu et al. [21] with some changes summarized as follows: Aspirate $1 \mathrm{ml}$ sample solution, add $5 \mathrm{ml}$ of $96^{\circ}$ ethanol, refrigerate $4^{\circ} \mathrm{C}$ for $24 \mathrm{~h}$. Centrifuge the precipitate, dissolve the precipitate, and make up to $5 \mathrm{ml}$ with warm water at $70^{\circ} \mathrm{C}$. Aspirate exactly $2 \mathrm{ml}$ of the sample the solution, add $8 \mathrm{ml}$ of anthrone reagent in concentrated sulfuric acid medium. Measure the absorbance at $630 \mathrm{~nm}$. The total polysaccharide content was calculated from the absorption value and the standard glucose equation (mg Glu/g sample).

Total saponin content determination. The total saponin content was carried out as described by Yang et al. [22] with some changes summarized as follows: Aspirate exactly $0.2 \mathrm{ml}$ of sample solution into the test tube. Add $0.3 \mathrm{ml}$ of vanilin $5 \%$ solution in glacial acetic acid and $1.4 \mathrm{ml} \mathrm{70 \%} \mathrm{perchloric} \mathrm{acid,} \mathrm{and} \mathrm{heat} \mathrm{in} \mathrm{a} \mathrm{water} \mathrm{bath} \mathrm{at}$ $70^{\circ} \mathrm{C}$ for $20 \mathrm{~min}$. Rapid cooling with ice for $2 \mathrm{~min}$, make up to $5 \mathrm{ml}$ with ethyl acetate, and photometric at $550 \mathrm{~nm}$. The total saponin content was calculated from the absorption value and the standard curve equation of 
oleanolic acid (mg/g sample).

Determination of the density of probiotic bacteria. One milliliter of fermentation solution or 1 gram of sample diluted to different concentrations was carried out on MRS agar. Samples were then density determined after $48 \mathrm{~h}$ of incubation at $37^{\circ} \mathrm{C}$.

Determination of $L$. plantarum viability under simulated gastric digestion after the spray drying process. The experiment was performed as described by Lieu et al. [21] simulated gastric fluid (SGF) consisting of $9 \mathrm{~g} / \mathrm{l}$ $\mathrm{NaCl}$ adjusted to $\mathrm{pH} 2.5$ with $5 \mathrm{M} \mathrm{HCl}$ and intestinal fluid (SIF) consisting of $9 \mathrm{~g} / \mathrm{l} \mathrm{NaCl}+3 \mathrm{ml} / \mathrm{l}$ cow bile was adjusted to $\mathrm{pH} 6.5$ with $5 \mathrm{M} \mathrm{NaOH}$.

The 4-gram sample was incubated in $36 \mathrm{ml}$ of SGF medium for $2 \mathrm{~h}$ at $37^{\circ} \mathrm{C}$, the sample was then transferred to SIF medium and incubated for $4 \mathrm{~h}$ at $37^{\circ} \mathrm{C}$. The viability of L. plantarum was indirectly examined on MRS medium after $48 \mathrm{~h}$ incubation at $37^{\circ} \mathrm{C}$.

\section{Statistical analysis}

All experiments were repeated three times, results presented as mean \pm standard deviation. Results are calculated and shown graph graphically by Sigma plot software. ANOVA analysis results with 95\% confidence, compare the differences between the treatments through the LSD and Tukey tests by Sigma plot software.

\section{Results and discussion}

\section{Effects of fermentation process on bioactive compounds} from Ngoc Linh ginseng callus and $L$. plantarum viability

The effect of lactic fermentation on the content of bioactive compounds in Ngoc Linh ginseng callus and $L$. plantarum viability was presented in Figs. 2 and 3. The results showed that fermentation time had a significant effect means $(p<0.05)$ when the density of $L$. plantarum changed from $6 \log \mathrm{CFU} / \mathrm{ml}$ to $8 \log \mathrm{CFU} / \mathrm{ml}$. Considering the same time of fermentation (from 8 to $36 \mathrm{~h}$ of fermentation), the initial cell concentration at $8 \log \mathrm{CFU} / \mathrm{ml}$ had a significantly higher total polyphenol content $(p<.05)$ than the other tests. The total content of polyphenols, polysaccharides, and saponins increased over time and reached a high level after 16 to $20 \mathrm{~h}$ of fermentation at a density of $8 \mathrm{log} \mathrm{CFU} / \mathrm{ml}$, whereas at lower concentrations (6 and $7 \log \mathrm{CFU} / \mathrm{ml}$ ), more time was needed to reach the highest content (Figs. 2 and 3). At a density of L. plantarum $8 \mathrm{Log}$ CFU/ml, the total content of polyphenols, polysaccharides, and saponins reached $(5.16 \pm 0.18) \mathrm{mg} \mathrm{GAE} / \mathrm{g}$ sample, $(277.2 \pm 6.12) \mathrm{mg} \mathrm{Glu} / \mathrm{g}$

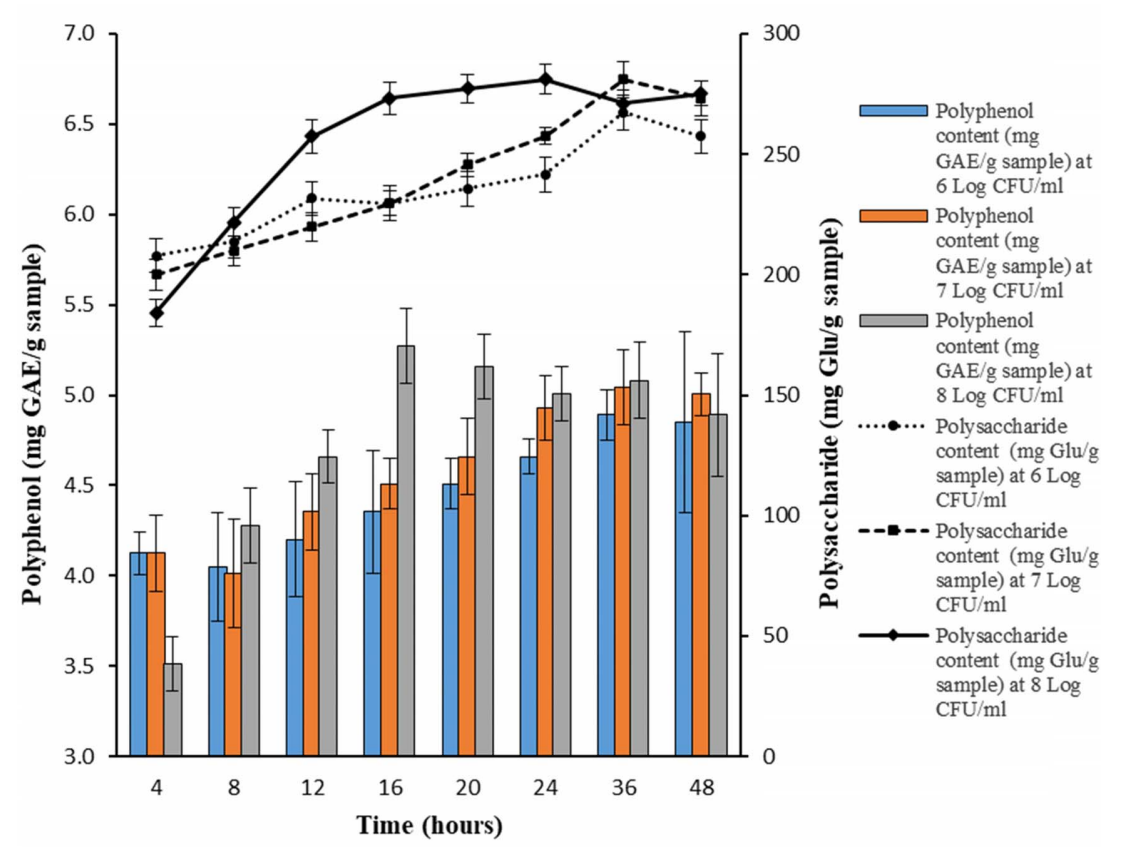

Fig. 2. The effect of lactic fermentation at different initial densities on polyphenol and polysaccharide content. 


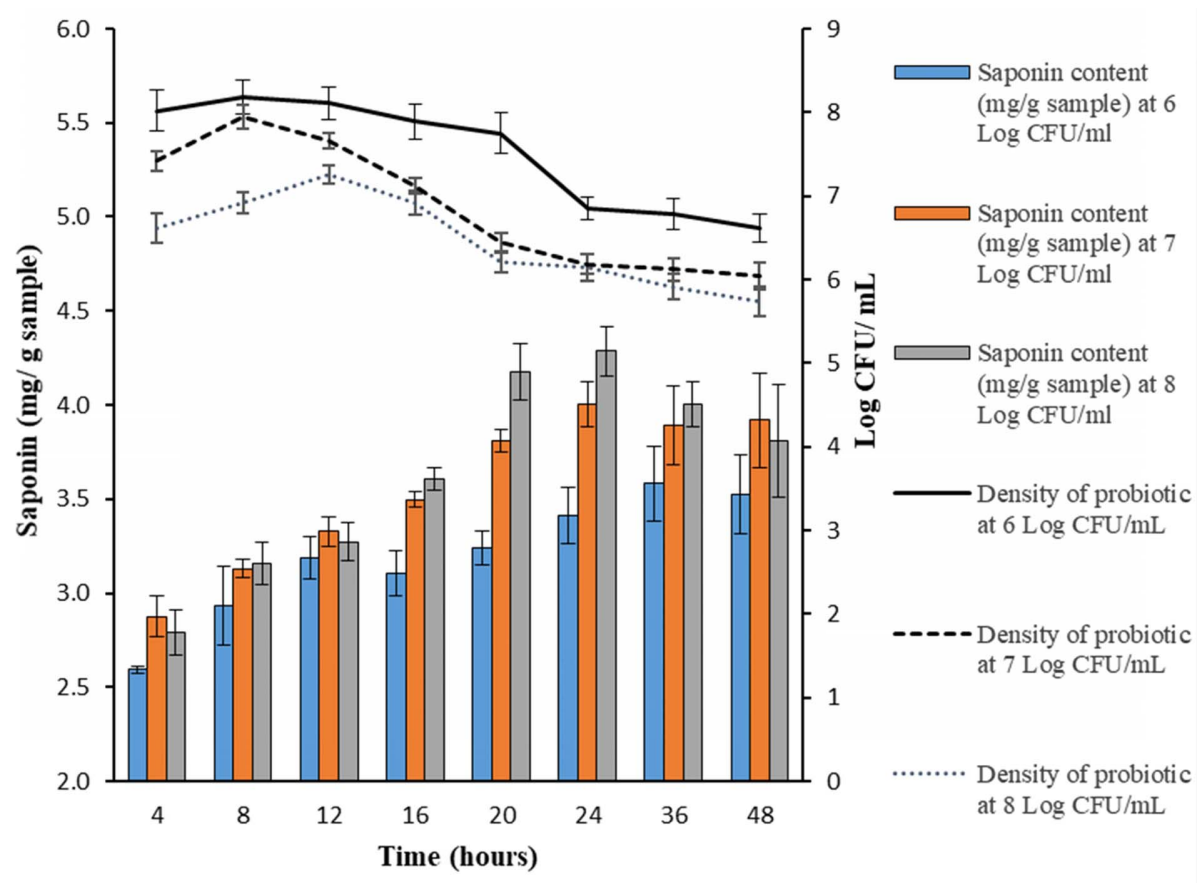

Fig. 3. The effect of lactic fermentation at different initial densities on saponin content and L. plantarum viability.

sample, and $(4.17 \pm 0.15) \mathrm{mg} / \mathrm{g}$ sample after $20 \mathrm{~h}$ of fermentation significantly higher $(p<0.05)$ than control samples with content $(3.82 \pm 0.31) \mathrm{mg}$ GAE/g sample, $(198 \pm 12.05) \mathrm{mg}$ Glu/g sample and $(2.82 \pm 0.32) \mathrm{mg} / \mathrm{g}$ sample, respectively.

The L. plantarum viability also showed significant changes during fermentation (Fig. 3). In general, cell density was increased slightly and stabilized in the first $20 \mathrm{~h}$ of the fermentation and then showed signs of a sharp decrease after $24 \mathrm{~h}$. The results obtained from the study showed that the content of bioactive compounds increased the highest after $24 \mathrm{~h}$ of fermentation. However, these contents at this time were not significant $(p>0.05)$ compared to fermented $20 \mathrm{~h}$ as well as the density of $L$. plantarum decreased sharply after $24 \mathrm{~h}$. Therefore, the 20-hour fermentation time was the most effective in this study (Figs. 2 and 3).

In previous studies showed that lactic acid bacteria could inhibit pathogenic bacteria and reduce food spoilage [11]. Besides, lactic fermentation significant impact on the bioactive compounds from plants [12, 23]. Hou et al. (2000) indicated that the content of polysaccharide, polyphenol increased significantly after fermentation of soy milk [24]. Bhat et al. (2015) suggested that it is only possible that fermentation microorganisms decompose polyphenol complexes resulting in increased phenolic content [23]. The results obtained from this study showed that the content of polysaccharide, polyphenol, and saponin increased during the fermentation process (Figs. 2 and 3). Besides, the fermentation time also affected the content of the bioactive compounds, in which the prolongation of the fermentation time caused negative impacts on the bioactive compounds (Figs. 2 and 3). Guava fermentation by L. plantarum significantly increased the polyphenol content and reached the peak value after $16 \mathrm{~h}$ of fermentation [23]. Hashemi et al. (2017) indicated that the decreasing of phenolic compounds could be mainly attributed to phenolic compounds metabolism enhanced by L. plantarum [25]. According to Moudsvi et al. (2011), L. plantarum consumed both glucose and fructose for metabolism, and during pomegranate fermentation, sugar content decreased significantly after $48 \mathrm{~h}$ of fermentation [26].

Besides, the prolonged fermentation time showed to affect the content of bioactive compounds as well as the viability of lactic bacteria (Figs. 2 and 3). The low $\mathrm{pH}$ environment containing acetic and lactic acids at a high concentration affected lactic bacteria [27]. This causes 
the viability of $L$. plantarum and L. acidophilus to decrease after $24 \mathrm{~h}$ of pomegranate juice fermentation [28], as well as after $20 \mathrm{~h}$ of fermentation from Ngoc Linh ginseng callus at $8 \mathrm{log} \mathrm{CFU} / \mathrm{ml}$ initial density of this study (Fig. 3). In the case of increasing probiotic density (up to $9 \mathrm{Log} \mathrm{CFU} / \mathrm{ml}$ ), the bioactive compounds content and fermentation time was no significant difference compared to that of $8 \mathrm{Log} \mathrm{CFU} / \mathrm{ml}$ (data not shown). The present study showed that the probiotic density has a significant effect on bioactive compounds in which the L. plantarum at $8 \log \mathrm{CFU} / \mathrm{ml}$ of concentration showed the best results with the short time fermentation compared to other tests (Figs. 2 and 3). This would be due to the high probiotic density increased the number of enzymes require for the extraction and metabolism of substances in the environment.

\section{Effects of spray drying process on bioactive compounds and $L$. plantarum viability after the fermentation process of Ngoc Linh ginseng}

The effect of maltodextrin with or without stevia supplement on encapsulation efficiency of bioactive compounds and L. plantarum viability during the spray drying process was presented in Fig. 4. There were differences among samples in which adding stevia had a possible impact on the recovery capacity of bioactive compounds from Ngoc Linh ginseng callus. In the control samples, the encapsulation efficiency of polyphenols, polysaccharides, and saponins after spray drying was $49 \%$; $61.67 \%$; and $49.35 \%$ respectively. In the samples containing stevia $3 \%$ and $6 \%(\mathrm{v} / \mathrm{v})$, the encapsulation

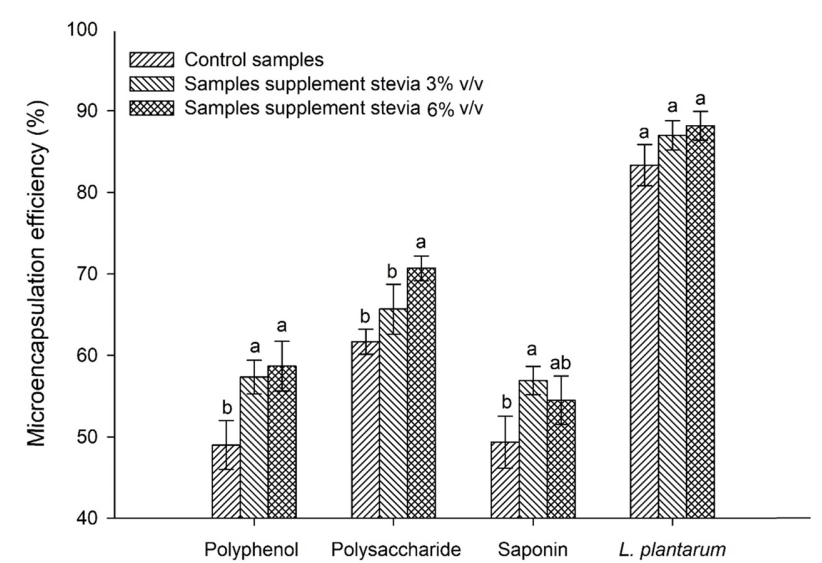

Fig. 4. Effect of spray drying on bioactive compounds and L. plantarum viability. efficiency was $57.33 \%$ and $58.67 \%$; $65.67 \%$ and $70.67 \%$; $56.91 \%$ and $54.49 \%$ correspond to polyphenols, polysaccharides, and saponins (Fig. 4). The addition of stevia to the spray drying process showed to improve the encapsulation efficiency of bioactive compounds $(p<0.05)$ compared to the control samples. The viability of $L$. plantarum with maltodextrin acting as the main wall material (with or without stevia) also showed slight differences between samples (Fig. 4). After the spray drying process, the survival rate of $L$. plantarum in the control samples was $83.33 \%$, whereas the samples supplement stevia $3 \%$ and $6 \%$ was $87 \%$ and 88.17 , respectively. However, there was no significant difference $(p>0.05)$ between these tests. Fig. 5 showed the SEM micrographs of particles with different microencapsulation agents. In general, the structure of the particle surface in all tested samples was similar. The particles showed spherical shapes and the concave surface structure of all samples.

Ensuring the bioactive compounds and probiotic source during storage time after fermentation is necessary, and the spray-drying technique could provide this value. This method's produce can easily transport, increased storage time [15]. The product capsule size from spray drying was significantly smaller than other prevalent techniques [27]. This helps to minimize its influence on the sensory properties of foods. However, this method also impacts the components using for spray drying. The effect of the spray drying process on the surface structure of microencapsulation particles has been reported in previous studies. A previous study using wall materials including maltodextrin, whey protein, and galacto-oligosaccharides in combination or individual indicated that there was no difference in the surface structure of particles among these preparations [16]. Similarly, Fritzen-Freire et al. (2012) suggested that spray-drying temperature and normal drying process caused the hole on the particle surface, and this phenomenon was not affected by the microencapsulation agents [29]. Though there was no difference in particle structure of preparation, the difference in microencapsulation efficiency of different wall materials has been reported. There are many wall materials, of which maltodextrin was commonly used and has been proven to improve the encapsulation efficiency of bioactive compounds and probiotic viability in the adverse environ- 
ment [16, 17, 30]. According to Anekella et al. (2013), maltodextrin has a role in supporting spray drying, increasing the wall material concentration, and improving the probiotic viability [17]. During the spray drying process, high temperature and wall material components were among the factors that significantly affect the bioactive compounds and probiotic source [16, 30]. High temperature adversely affects the structure of sensitive bioactive compounds. A study by Tchabo et al. (2019) indicated that the content of phenolic acids, flavonol, and other bioactive compounds reduced remarkably when the inlet temperature increased from $120^{\circ} \mathrm{C}$ to $160^{\circ} \mathrm{C}$ [30]. Similarly, losses of total phenolic compounds during spray drying (inlet temperature was $140^{\circ} \mathrm{C}$ ) reached $76-78 \%$ on average in Blueberry juice [31]. Besides, the high temperature of the spray drying also significantly affected probiotic bacteria. The probiotic viability would be reduced by $55 \%$ increasing the inlet temperature to $130^{\circ} \mathrm{C}$ [17], and up to $80 \%$ increasing the inlet temperature was $155^{\circ} \mathrm{C}$ [32]. However, the spray drying temperature below $120^{\circ} \mathrm{C}$ results in low powder yield and high moisture [30]. These show that depends on the type of fluid need the suit spray drying parameters ensuring the microencapsulation efficiency of bioactive compounds and probiotic viability after spray drying. In the present study, the inlet temperature of $120^{\circ} \mathrm{C}$ showed the ability to microencapsulate the bioactive compounds and $L$. plantarum viability effectively (Fig. 4).

The wall material components have been proven to affect the microencapsulation efficiency [14]. The combination of maltodextrin with other wall materials showed to improve the microencapsulation efficiency [16, 33]. Maltodextrin combined with whey protein significantly enhanced $L$. casei viability during the spray drying pro- cess compared to that of the only maltodextrin [16]. Similarly, research by Kalita et al. (2018) indicated that the combination of maltodextrin and fructooligosaccharide (FOS) improved the L. plantarum viability after the spray drying process [33]. The role of stevia on the microencapsulation efficiency of bioactive compounds from Ngoc Linh ginseng by spray drying technique has not been fully reported. The components of stevia, such as steviol glycoside, FOS, etc., play an important role in the growth of probiotic bacteria [34, 35]. The present study showed that the bioactive compound contents and L. plantarum viability in the samples containing stevia were higher than that of the only maltodextrin. This suggested that a stevia supplement was necessary to improve the microencapsulation efficiency of bioactive compounds, as well as improve product sensory at lowcalorie. The microencapsulation efficiency was not significantly improved when increasing the stevia concentration to $9 \%(\mathrm{v} / \mathrm{v})$ compared to that of $6 \%(\mathrm{v} / \mathrm{v})$ (data not shown). However, with the sweet level is 300 times greater than sucrose [18], increasing stevia concentration would affect the product sensory and the characteristic flavor of Ngoc Linh ginseng.

\section{Effects of simulated gastric digestion on L. plantarum viability after the spray drying process}

The effect of SGF and SIF on L. plantarum viability after spray drying was presented in Fig. 6. The $L$. plantarum showed significant differences between samples (Fig. 6). In the SGF condition, the L. plantarum viability in control samples was remarkably reduced with $3.22 \mathrm{Log}$ CFU/g cell loss, which was significantly higher than the samples containing stevia $3 \%$ and $6 \%$ (v/v) corresponding to $2.06 \log \mathrm{CFU} / \mathrm{g}$ and $1.77 \mathrm{Log} \mathrm{CFU} / \mathrm{g}$ cell loss. The L. plantarum viability in all samples

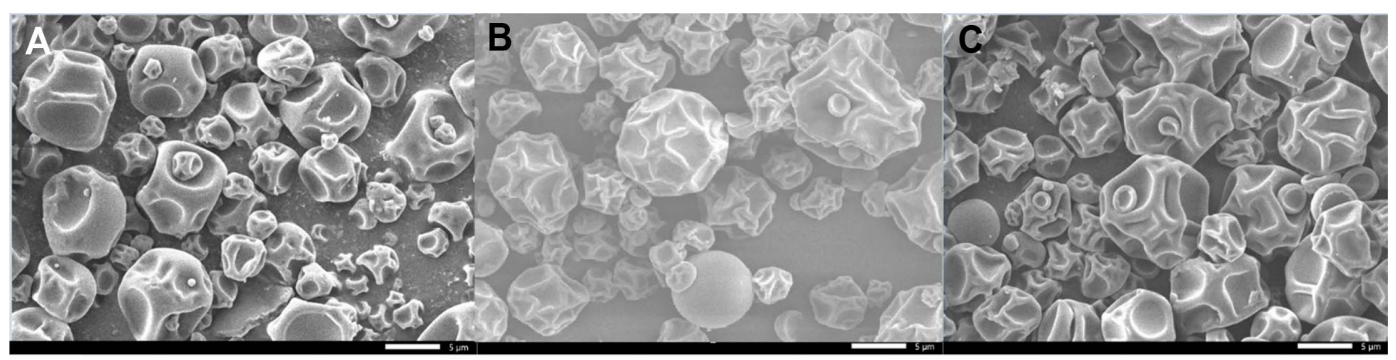

Fig. 5. Surface morphology of preparations; (A) control sample, (B) samples supplement with stevia $3 \% \mathrm{v} / \mathrm{v}$, and (C) samples supplement with stevia $6 \% \mathrm{v} / \mathrm{v}$. 


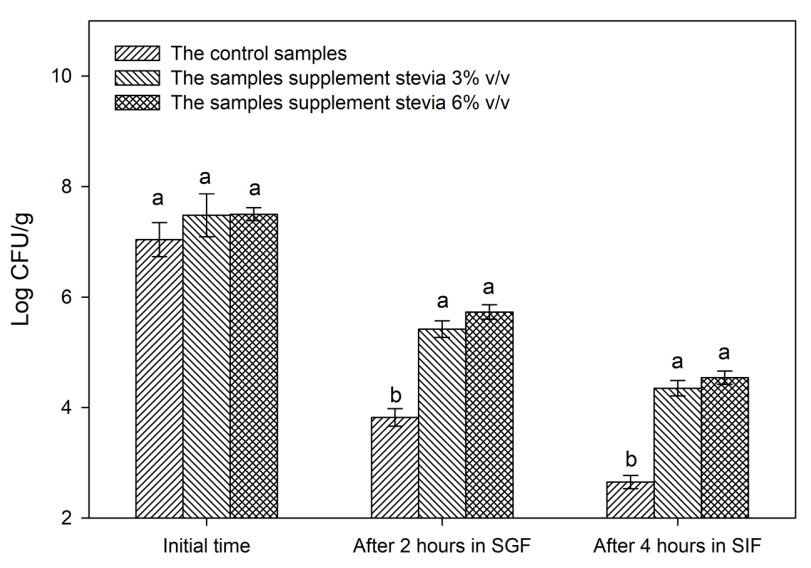

Fig. 6. Survival of $L$. plantarum strains under SGF and SIF conditions after spray drying.

continued to decrease after transferring to SIF condition (Fig. 6). However, the amount of L. plantarum cell loss in SIF condition was not significantly different between these samples. The adding stevia remarkably improved the L. plantarum viability in simulated gastric digestion compared to the control samples. Though the $L$. plantarum viability in the samples containing stevia $6 \%$ $(\mathrm{v} / \mathrm{v})$ was trended to higher than that of $3 \%(\mathrm{v} / \mathrm{v})$, this difference was not significant (Fig. 6).

The probiotic viability under gastrointestinal conditions is necessary to ensure the benefits this microorganism brings. The low $\mathrm{pH}$ and digestion enzymes of the SGF condition were significantly lethal to probiotics compared to the SIF condition [16]. The previous evaluations have shown that free probiotic cells could not overcome the SGF condition [27]. Therefore, the microencapsulating probiotic is essential to help these strains overcome this adverse medium and provide health value. A previous study showed that microencapsulation by spray drying with maltodextrin as wall material improved $L$. casei viability in SGF and SIF with the survival rate of $33.92 \%$ and $69.65 \%$, respectively [16]. Anekella et al. (2013) indicated that maltodextrin also acts as a prebiotic source [17], which enhances probiotic viability under these conditions (Fig. 6). These suggested that maltodextrin is a suit wall material that improves probiotic viability under gastrointestinal conditions. Besides, the combination of maltodextrin with other wall material also has been proven to improve probiotic viability. Kalita et al. (2018) suggested that the combination of maltodextrin and FOS was necessary to protected
L. plantarum in the gastric environment [33]. Similarly, spray drying with the mix of maltodextrin and whey protein as wall material improves Lactobacillus casei viability during storage, as well as under the SGF condition compared to that of the only maltodextrin [16]. The effect of stevia on probiotic viability was also reported in previous studies showed that steviol glycoside from Stevia rebaudiana is considered a substrate source for the growth of L. plantarum and Lactobacillus acidophilus [34, 35]. In addition, Lopes et al. (2016) indicated that FOS from $S$. rebaudiana is a prebiotic source that enhanced the growth of Bifidobacteria and Lactobacilli [36]. A study by Kim et al. (2016) showed that microorganism density in fermented milk adding $S$. rebaudiana was increased during $9 \mathrm{~h}$ of fermentation [37]. Lemus et al. (2016) suggested that $S$. rebaudiana containing high sweet levels at low-calorie is a valuable source for tea products [18]. These suggested that S. rebaudiana is necessary for probiotic growth, as well as improves product sensory.

In summary, the fermentation time, and the $L$. plantarum density significantly influenced the bioactive compounds of Ngoc Linh ginseng callus. The L. plantarum at $8 \log \mathrm{CFU} / \mathrm{ml}$ of concentration showed the best results with the short time fermentation compared to other tests. The addition of stevia as supplement wall material showed to improve the encapsulation efficiency of bioactive compounds and $L$. plantarum viability compared to that of the maltodextrin only. The results also indicated that adding S. rebaudiana improved the L. plantarum viability in gastric digestion. The L. plantarum viability in control samples was remarkably reduced compared to the samples containing stevia in the SGF test. However, the amount of $L$. plantarum cell loss in SIF condition was not significantly different between these samples. These results suggested that the supplement of stevia was necessary to improve the microencapsulation efficiency of bioactive compounds, the L. plantarum viability, as well as improve product sensory at lowcalorie.

\section{Acknowledgments}

The authors express their deepest gratitude to the Faculty of Food Science and Technology, Ho Chi Minh City University of Food Industry, and Department of Plant Cell Technology, Institute of Tropical Biology, Ho Chi Minh City, Vietnam for providing research facilities. 


\section{Conflict of Interest}

The authors have no financial conflicts of interest to declare.

\section{References}

1. Konoshima T, Takasaki M, Ichiishi E, Murakami T, Tokuda H, Nishino $H$, et al. 1999. Cancer chemopreventive activity of majonoside-R2 from Vietnamese ginseng, Panax vietnamensis. Cancer Lett. 147: 11-16.

2. Jeong JJ, Van LTH, Lee SY, Eun SH, Nguyen MD, Park JH, et al. 2015. Anti-inflammatory effects of vina-ginsenoside R2 and majonoside R2 isolated from Panax vietnamensis and their metabolites in lipopolysaccharide-stimulated macrophages. Int. Immunopharmacol. 28: 700-706.

3. dela Peña IJ, Kim HJ, Botanas CJ, De La Pena JB, Van Le TH, Nguyen MD, et al. 2017. The psychopharmacological activities of Vietnamese ginseng in mice: characterization of its psychomotor, sedative-hypnotic, antistress, anxiolytic, and cognitive effects. J. Ginseng Res. 41: 201-208.

4. Yamasaki K. 2000. Bioactive saponins in Vietnamese ginseng, Panax vietnamensis. Pharm. Bbiol. 38: 16-24.

5. Kevers C, Jacques P, Gaspar T, Thonart P, Dommes J. 2004. Comparative titration of ginsenosides by different techniques in commercial ginseng products and callus cultures. J. Chromatogr. Sci. 42: 554-560.

6. Olennikov DN, Tankhaeva LM, Partilkhaev VV, Rokhin AV. 2012. Chemical constituents of Caragana bungei shoots. Rev. Bras. Farmacogn. 22: 490-496.

7. Kwon, JH, Bélanger JM, Paré JJ. 2003. Optimization of microwaveassisted extraction (MAP) for ginseng components by response surface methodology. J. Agric. Food Chem. 51: 1807-1810.

8. Wu J, Lin L, Chau F. 2001. Ultrasound-assisted extraction of ginseng saponins from ginseng roots and cultured ginseng cells. Ultrason. Sonochem. 8: 347-352.

9. Chen XC, Zhu YG, Zhu LA, Huang C, Chen Y, Chen LM, et al. 2003. Ginsenoside $\mathrm{Rg} 1$ attenuates dopamine-induced apoptosis in PC12 cells by suppressing oxidative stress. Eur. J. Pharmacol. 473: 1-7.

10. Narayanan N, Roychoudhury P, Srivastava A. 2004. L (+) lactic acid fermentation and its product polymerization. Electron. $J$. Biotechnol. 7: 167-178.

11. Leroy F, De VL. 2004. Lactic acid bacteria as functional starter cultures for the food fermentation industry. Trends Food Sci. Technol. 15: 67-78.

12. Hur SJ, Lee SY, Kim YC, Choi I, Kim GB. 2014. Effect of fermentation on the antioxidant activity in plant-based foods. Food Chem. 160: 346-356.

13. Aymerich T, Artigas M, Garriga M, Monfort J, Hugas M. 2000. Effect of sausage ingredients and additives on the production of enterocin A and B by Enterococcus faecium CTC492. Optimization of in vitro production and anti-listerial effect in dry fermented sausages. J. Appl. Microbiol. 88: 686-694.
14. Patel R, Patel $M$, Suthar A. 2009. Spray drying technology: an overview. Indian J. Sci. Technol. 2: 44-47.

15. Menshutina NV, Gordienko MG, Voinovskiy AA, Zbicinski I. 2010. Spray drying of probiotics: process development and scale-up. Drying Technol. 28: 1170-1177.

16. Lieu MD, Dang TKT, Nguyen TH. 2017. Viability of microencapsulated Lactobacillus casei in synbiotic mayonnaise. Food Res. 1: 234-239.

17. Anekella K, Orsat V. 2013. Optimization of microencapsulation of probiotics in raspberry juice by spray drying. LWT-Food Sci. Technol. 50: 17-24.

18. Lemus-Mondaca R, Ah-Hen K, Vega-Gálvez A, Honores C, Moraga NO. 2016. Stevia rebaudiana leaves: effect of drying process temperature on bioactive components, antioxidant capacity and natural sweeteners. Plant Foods Hum. Nutr. 71: 49-56.

19. Lopes SMS, Krausová G, Carneiro JWP, Gonçalves JE, Gonçalves RAC, de Oliveira AJB. 2017. A new natural source for obtainment of inulin and fructo-oligosaccharides from industrial waste of Stevia rebaudiana Bertoni. Food Chem. 225: 154-161.

20. Leamsomrong K, Suttajit M, Chantiratikul P. 2009. Flow injection analysis system for the determination of total phenolic compounds by using Folin-Ciocalteu assay. Asian J. Appl. Sci. 2: 184190.

21. Lieu MD, Le TKN, Nguyen TL, Dang TKT, Do DG. 2020. Effect of calcium-alginate bead and Anoectochilus formosanus Hayata extract fluid on the viability of Lactobacillus plantarum ATCC 8014 and bioactive compounds in fermented apple juice. Food Res. 4: 652-658.

22. Yang Y, Chen L, Zhang XX, Guo Z. 2004. Microwave assisted extraction of major active ingredients in Panax quinquefolium $\mathrm{L}$. J. Lliq. Chromatogr. Relat. Technol. 27: 3203-3211.

23. Bhat R, Suryanarayana LC, Chandrashekara KA, Krishnan P, Kush A, Ravikumar P. 2015. Lactobacillus plantarum mediated fermentation of Psidium guajava L. fruit extract. J. Biosci. Bioeng. 119: 430-432.

24. Hou JW, Yu RC, Chou CC. 2000. Changes in some components of soymilk during fermentation with bifidobacteria. Food Res. Int. 33: 393-397.

25. Hashemi SMB, Khaneghah AM, Barba FJ, Nemati Z, Shokofti SS, Alizadeh F. 2017. Fermented sweet lemon juice (Citrus limetta) using Lactobacillus plantarum LS5: Chemical composition, antioxidant and antibacterial activities. J. Funct. Foods 38: 409-414.

26. Mousavi Z, Mousavi S, Razavi S, Emam-Djomeh Z, Kiani H. 2011. Fermentation of pomegranate juice by probiotic lactic acid bacteria. World J. Microbiol. Biotechnol. 27: 123-128.

27. Rokka S, Rantamäki P. 2010. Protecting probiotic bacteria by microencapsulation: challenges for industrial applications. Eur. Food Res. Technol. 231: 1-12.

28. Mousavi ZE, Mousavi SM, Razavi SH, Hadinejad M, EmamDjomeh Z, Mirzapour M. 2013. Effect of fermentation of pomegranate juice by Lactobacillus plantarum and Lactobacillus acidophilus on the antioxidant activity and metabolism of sugars, organic acids and phenolic compounds. Food Biotechnol. 
27: 1-13.

29. Fritzen-Freire $C B$, Prudêncio ES, Amboni RD, Pinto SS, NegrãoMurakami AN, Murakami FS. 2012. Microencapsulation of bifidobacteria by spray drying in the presence of prebiotics. Food Res. Int. 45: 306-312.

30. Tchabo W, Ma Y, Kaptso GK, Kwaw E, Cheno RW, Xiao L, et al. 2019. Process analysis of mulberry (Morus alba) leaf extract encapsulation: Effects of spray drying conditions on bioactive encapsulated powder quality. Food Bioprocess Technol. 12: 122146.

31. Wilkowska A, Ambroziak W, Czyżowska A, Adamiec JJPJF, Sciences N. 2016. Effect of microencapsulation by spray-drying and freeze-drying technique on the antioxidant properties of blueberry (Vaccinium myrtillus) juice polyphenolic compounds. Polish J. Food Nutr. Sci. 66: 11-16.

32. Avila-Reyes SV, Garcia-Suarez FJ, Jiménez MT, San Martín-Gonzalez MF, Bello-Perez LA. 2014. Protection of L. rhamnosus by spraydrying using two prebiotics colloids to enhance the viability. Carbohydr. Polym. 102: 423-430.

33. Kalita D, Saikia S, Gautam G, Mukhopadhyay R, Mahanta CLL.
2018. Characteristics of synbiotic spray dried powder of litchi juice with Lactobacillus plantarum and different carrier materials. LWT 87: 351-360.

34. Li S, Chen T, Dong S, Xiong Y, Wei H, Xu F. 2014. The effects of rebaudioside $A$ on microbial diversity in mouse intestine. Food Sci. Technol. Res. 20: 459-467.

35. Ozdemir T, Ozcan T. 2020. Effect of steviol glycosides as sugar substitute on the probiotic fermentation in milk gels enriched with red beetroot (Beta vulgaris L.) bioactive compounds. LWT 134: 109851.

36. Lopes SMS, Francisco MG, Higashi B, de Almeida RTR, Krausová G, Pilau EJ, et al. 2016. Chemical characterization and prebiotic activity of fructo-oligosaccharides from Stevia rebaudiana (Bertoni) roots and in vitro adventitious root cultures. Carbohydr. Polym. 152: 718-725.

37. Kim HN, Yoon JW, Moon SA, Choi SB, Seo YM, Park J, et al. 2016. Fermentation and quality characteristics during the storage of greek-style yogurt supplemented with stevia leaf extract. J. Milk Sci. Biotechnol. 34: 51-57. 